\title{
Extensive micro-geographical shell polymorphism in a planktotrophic marine intertidal snail
}

\author{
V. Cuña ${ }^{1}$, M. Saura ${ }^{2}$, H. Quesada ${ }^{2}$, E. Rolán-Alvarez ${ }^{2, *}$ \\ ${ }^{1}$ Laboratorio de Imunogenética, Instituto Butantan, São Paulo, SP, Brazil \\ ${ }^{2}$ Departamento de Bioquímica, Genética e Inmunología, Facultad de Biología, 36310 Vigo, Spain
}

\begin{abstract}
Intertidal species inhabiting Galician rocky shores are exposed to a strong vertical gradient in environmental and ecological conditions. Such a gradient is determined by a combination of wave action (impacting the low shore in particular) as well as heat, osmotic stress and predation (impacting the high shore in particular). In this area, 2 convergent shell polymorphisms have previously been described in 2 marine gastropod species with direct development, Littorina saxatilis and Nucella lapillus. These distinct morphotypes occur sympatrically at the same shore at different levels, as a result of environmental adaptation. In the present work, we combine geometric morphometrics with the study of amplified fragment length polymorphism (AFLP) variation to investigate whether a similar polymorphism is occurring in individuals of the planktotrophic gastropod species Melarhaphe neritoides across this geographical region. Although no consistent genetic differentiation was found for AFLP, 2 distinct ecomorphs, similar to those already described in the other 2 species, were detected by morphometric analysis. Analyses of variance supported significant variation between morphs in 3 separate localities. The 2 morphs maintained most of their shell shape (and behavioural) differences when reared in laboratory conditions. These results suggest an adaptive role for the described polymorphism in size and shell shape although further studies are required to identify the genetic and evolutionary mechanisms favouring the maintenance of this pattern in sympatry in a high dispersal species.
\end{abstract}

KEY WORDS: Adaptive $\cdot$ AFLP $\cdot$ Ecological speciation $\cdot$ Melarhaphe $\cdot$ Natural selection $\cdot$ Phenotypic convergence $\cdot$ Phenotypic plasticity $\cdot$ Sympatry

\section{INTRODUCTION}

Since the 'Origin of species' (Darwin 1859), evolutionary biologists have been fascinated by adaptive variation, as well as by the evolutionary mechanism (natural selection) causing it (Endler 1986). Natural selection will act on the available phenotypes increasing the frequency of those that maximise the individuals' efficiency when competing for mates and resources. However, the phenotype is a complex set of traits resulting from the interplay between genetic information (genotypes) and environmental features (Karban \& Baldwin 1997, Schlichting \& Pigliucci 1998, Tollrian \& Harvell 1999, Pigliucci 2001, 2005, West-Eberhard 2002, Miner 2003). When exposed to different environments, the same genotype may result in distinct phe- notypes, a phenomenon known as phenotypic plasticity in an ecological context and standard reaction norm in a quantitative genetic one (Falconer \& Mackay 1996, Sarkar \& Fuller 2003, Pigliucci 2005). Genes affecting such plastic responses are interesting for evolutionary biologists, as they may greatly contribute to species adaptation (West-Eberhard 1989, Brönmark \& Miner 1992, DeWitt et al. 1998, Scheiner 1998, Pigliucci 2001, 2005, Langerhans \& DeWitt 2002, DeWitt \& Scheiner 2004, Hollander et al. 2006). In fact, natural selection may maintain adaptive polymorphisms in a population by acting either on loci directly coding for the trait polymorphism ('direct adaptation') or on loci controlling the phenotypic plastic response of the trait ('indirect adaptation') (Scheiner 1993, Fordyce 2006, Garland \& Kelly 2006, Pigliucci et al. 2006, Price 2006). 
Adaptive strategies producing environmentally induced phenotypes can change during ontogeny (Schlichting \& Pigliucci 1998, West-Eberhard 2002). Environmental factors present during early development can produce life-long imprints that condition the adult stage (Remy 2010). This early imprinting is highly conserved in evolution and is an important form of adaptive behavioural plasticity (Lorenz 1970). There are significant differences in the degree of reversibility of different kinds of plasticity. Typically, biochemical and physiological responses can be reversed over short time scales, while developmental plasticity tends to be irreversible or takes longer to be reversed (Pigliucci et al. 2006).

Intertidal rocky shore areas are extremely heterogeneous habitats in time, although they are predictable enough to produce strong environmental gradients from lower to upper shores (Raffaelli \& Hawkins 1996). On exposed areas of Galician shores (NW Spain), the impact of wave action is higher in lower shore areas that are open to the sea, while heat, osmotic stress and predation affect mostly the upper shore areas (RolánAlvarez 2007), thus producing marked micro-habitat differences. Such environmental patterns are specific to this region and its particular characteristics, as this pattern is reversed in British cliffs (Johannesson et al. 2010). Marine intertidal gastropods from such microhabitats are very interesting for the study of ecological adaptation, as they show a worldwide distribution and frequent polymorphisms, and the ecological factors and biological interactions in their habitats can often be directly observed (Vermeij 1973, Etter 1996).

On Galician wave-exposed rocky shores, 2 convergent shell polymorphisms have been described in 2 different gastropod species with direct development: Littorina saxatilis (Olivi 1972) and Nucella lapillus (L.). In L. saxatilis, a small, smooth and unbanded ('SU') ecotype (hereafter referred to as exposed morph E) showing a short spire and large shell aperture is observed on the lower shore, living preferentially among mussels. In contrast, a large, ridged and banded ('RB') ecotype (hereafter referred to as sheltered morph S) showing a long spire with a small shell aperture is found on the upper shore, living among barnacles or within crevices (Rolán-Alvarez et al. 2004, Carvajal-Rodríguez et al. 2005, Conde-Padín et al. 2007). This polymorphism has been shown to be adaptive and maintained by strong disruptive selection acting across the intertidal environmental gradient (reviewed by Rolán-Alvarez 2007). On the lower shore, the main physical and ecological factor affecting survival is the swell strength. This explains the smaller and smooth shells of the E ecotype, to avoid displacement caused by waves (Johannesson et al. 1993) and also a larger shell aperture to accommodate a larger muscular foot for more effective attachment to the susbstratum (Carvajal-Rodríguez et al. 2005). On the upper shore, the risk of desiccation, a major osmotic stress, and the threat of crabs explain the smaller aperture of the shell of the S ecotype, as well as the stronger and ridged shells to resist crabs attacks (Rolán-Alvarez 2007). Different studies support a genetic basis for the ecotype differences (Johannesson et al. 1993, Rolán-Alvarez et al. 1997, Conde-Padín et al. 2007). The percentage of additive genetic variation that can explain the observed phenotypic variation has been directly estimated in the laboratory and in the wild (mean heritability $=0.5$ ), supporting a principal genetic component explaining variation within and between ecotypes (Carballo et al. 2001, Conde-Padín et al. 2007). Additionally, Conde-Padín et al. (2009) compared morphological data from individuals born in the laboratory and taken from the wild at different developmental stages (shelled embryos, juveniles and adults) and observed that most of the shape variation in adaptive traits was explained by ecotype independently of the growth environment.

On the same shores and with a similar distribution, 2 equivalent $\mathrm{E}$ and $\mathrm{S}$ ecotypes have been observed for the direct-developing gastropod Nucella lapillus (Rolán et al. 2004, Guerra-Varela et al. 2009), a typical predator of mussels, barnacles and other snails (Kitching et al. 1966). Morphological, genetic and markrecapture data suggest that this polymorphism is also adaptive. Heritability for shell traits was also estimated for this species (average $h^{2}=0.5$ ), with similar results to those obtained for Littorina saxatilis (Guerra-Varela et al. 2009). In summary, on the same shores and vertical levels, distinct ecotypes (exposed/sheltered) of 2 distantly related gastropod species (belonging to different superfamilies: Littorinoidea and Muricoidea, respectively) show convergent patterns of intraspecific variation with similar adaptive interpretations.

A third marine snail coexisting in the same area is Melarhaphe neritoides (L.), a small dioecius littorinid gastropod typically living on intertidal rocky shores of the Mediterranean and Southern Atlantic (Fretter \& Graham 1980). The species shows seasonal reproduction, releasing eggs that remain pelagic for 4 to $8 \mathrm{wk}$ before establishing as juvenile snails on a particular rocky shore (Johannesson 1992, Cronin et al. 2000). From an ecological point of view, it is known that this species typically seeks sheltered crevices, pits or other substratum irregularities to avoid direct radiant solar energy and thermal loading from direct contact with the substratum (Britton 1995). When protected from direct solar radiation, individuals from this species may lie exposed to air for weeks or even months (Britton 1992).

Although there are no previous studies describing morphological variation, field observations point to- 
wards the occurrence of a shell polymorphism in Melarhaphe neritoides. This species seems a priori a good candidate for showing important levels of phenotypic plasticity (Hollander 2008), rather than direct genetic adaptation. The life cycle, with a pelagic larval stage, suggests relatively high levels of gene flow along distant geographical areas (Johannesson 1992).

Our aim was first to investigate whether the pattern of shell polymorphism already described in Littorina saxatilis and Nucella lapillus, occurring in the same rocky shore gradient, is also confirmed in the planktotrophic gastropod species Melarhaphe neritoides. The coincidence of the same polymorphism in 3 different species inhabiting similar niches would preliminarily suggest an adaptive role for such a pattern in $M$. neritoides as well.

Therefore, to elucidate whether an adaptive polymorphism exists consistently at a micro-geographical scale across an extensive geographical region, and second (if confirmed) to disentangle the mechanism responsible for the maintenance of such polymorphism, we studied the morphological variability of $\mathrm{S}$ and $\mathrm{E}$ ecomorphs, analysed the genetic divergence between these morphs using amplified fragment length polymorphism (AFLP) markers, and performed laboratory rearing.

\section{MATERIALS AND METHODS}

Sampling. Geographical study: Samples were obtained during November and December 2006 across a $77 \mathrm{~km}$ range from 3 different wave-exposed localities of Galicia (NW Spain; Fig. 1A: Cetárea, 41 ${ }^{\circ} 55^{\prime} 1.64^{\prime \prime} \mathrm{N}$, $8^{\circ} 53^{\prime}$ 8.07" W; Silleiro, $42^{\circ} 6^{\prime} 17.20^{\prime \prime} \mathrm{N}, 8^{\circ} 53^{\prime} 56.59^{\prime \prime} \mathrm{W}_{\text {; }}$ and Corrubedo, $42^{\circ} 34^{\prime} 36.47^{\prime \prime} \mathrm{N}$, $9^{\circ} 5^{\prime} 28.67^{\prime \prime} \mathrm{W}$ ). In each locality, 2 extreme intertidal shore levels were sampled along 2 replicate transects (Fig. 2; T1 and T2). Snails were collected from 1 to $6 \mathrm{~m}^{2}$ plots at each combination of locality, shore level and transect, resulting in 12 samples with 20 to 30 individuals each (a total of 340 ind.). All 12 samples were analysed for variation in shell morphology. The 4 samples from Silleiro (96 ind.) were additionally screened for variation in AFLP markers.

Laboratory rearing study: Sexually immature juveniles from both intertidal gradient locations (size range of 1.8 to $2.5 \mathrm{~mm}$ ) were captured in March 2007 and transported to the ECIMAT field station laboratory (Marine Research Center, Toralla, Vigo, Spain). They were distributed into 2 different glass containers of $21 \mathrm{l}$ each, with

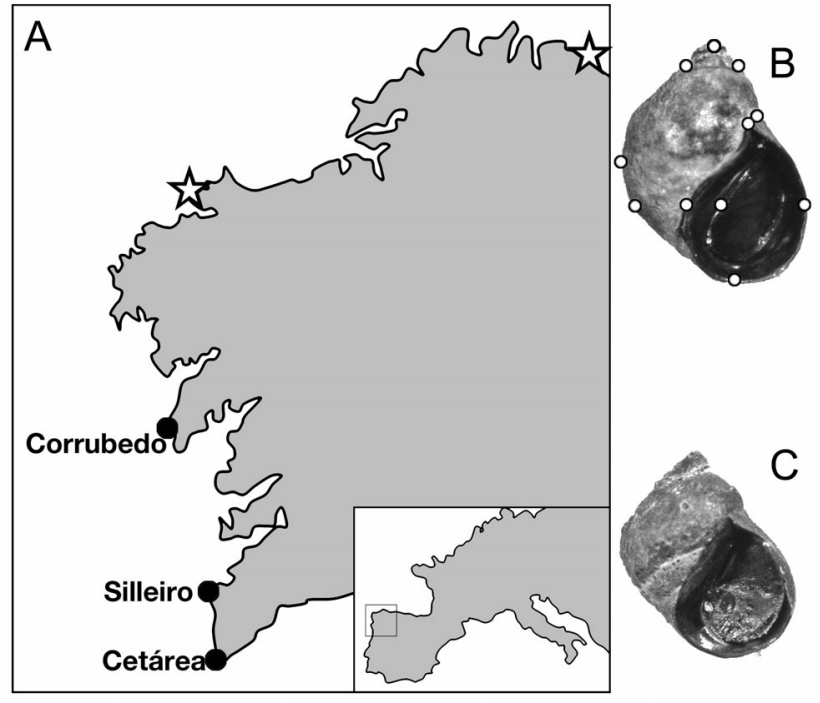

Fig. 1. Melarhaphe neritoides. (A) Sampling locations in Galicia, NW Spain. = sampling sites; it = additional locations in which the 2 morphs have been observed. $(B, C)$ Shell morphotypes studied in the present work (B: sheltered morph from upper shore, white dots = landmarks used in the geometric morphometrics analysis; C: exposed morph from lower shore)

some shore stones and an open circuit of continuous water flow $\left(30 \mathrm{l} \mathrm{h}^{-1}\right)$. The seawater was oxygenated by 6 diffusers included in each container to assure that the entering water carried an oxygenation supplement. Sea water temperature was $14.2^{\circ} \mathrm{C}$, with a salinity of $36.3 \%$ and an oxygen content of $7.6 \mathrm{mg} \mathrm{l}^{-1}$. The photoperiod was naturally regulated with no additional light. In both aquaria, inocula of diatoms (Cylindrotheca closterium and Nitzschia spp.) were introduced as a nourishing supplement following the methodology of Conde-Padín et al. (2008). Forty Melarhaphe neritoides specimens (20 of each morph) were maintained during $9 \mathrm{mo}$ in these conditions, and during this period, adult size was fully achieved (means \pm SD: S morph $=6.28 \pm 0.50 \mathrm{~mm} ;$ E morph $=4.78 \pm 0.53 \mathrm{~mm}$ ).

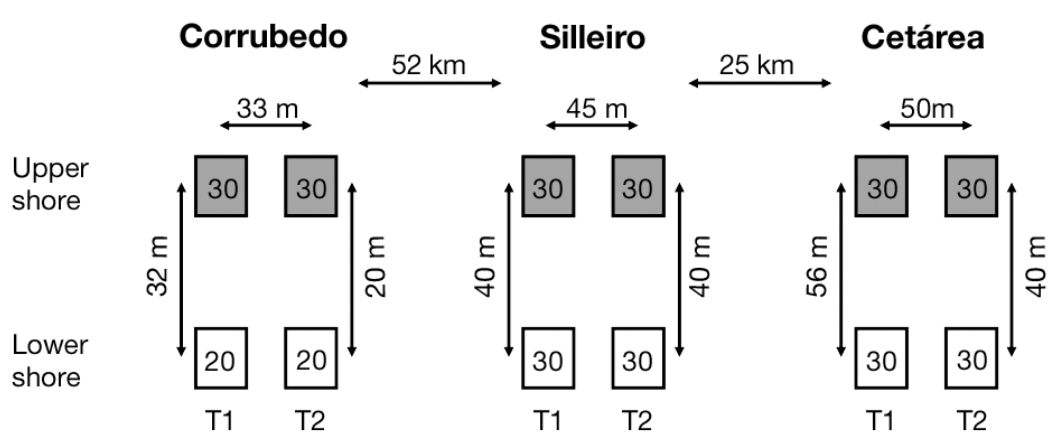

Fig. 2. Melarhaphe neritoides. Experimental design for the morphometric study. $\mathrm{T} 1, \mathrm{~T} 2$ = transects. Also given: distances between sampling sites, and number of collected ind. per site (rectangles). The amplified fragment length polymorphism (AFLP) study was carried out including only the samples from Silleiro 
After this period, 20 specimens from each morphotype were captured from the wild, with sizes similar to laboratory specimens ( $\mathrm{S}$ morph $=6.37 \pm 0.72 \mathrm{~mm}$; E morph $=4.91 \pm 0.22 \mathrm{~mm}$ ). The wild specimens used to perform laboratory versus wild comparisons were different from those used in the geographical study described above. The comparison between both environments and morphotypes allowed us to estimate the relative importance of plastic versus inherited effects for shell shape but not for size (see Scheiner 1998, Conde-Padín et al. 2008).

Morphometric measurements. Sampled specimens were examined using a Leica MZ12 stereoscopic microscope. Colour images were captured by a Leica digital ICA video camera. Shell images ( $\mathrm{N}=340$ and $\mathrm{N}=80$ for each experiment, respectively) were analysed using 10 landmarks (LM) positioned on the digitised shell image (Fig. 1), following the approach used for related snail species (Carvajal-Rodríguez et al. 2005, 2006, CondePadín et al. 2007, Guerra-Varela et al. 2009). For each specimen, size was measured by the centroid size (CS), whereas shape was measured by both the uniform component (U1 and U2) and the relative warps (RW; Rohlf \& Slice 1990, Bookstein 1991, Rohlf 1993, Rohlf \& Bookstein 2003, Zelditch et al. 2004, Carvajal-Rodríguez et al. 2005). RWs were computed excluding the uniform component (to study globosity separately), using the algorithm given by Rohlf (1993), following the procedure applied by Carvajal-Rodríguez et al. (2005). We used the scaling option $\alpha=0$, which weights all landmarks equally (Rohlf 1996). All calculations were performed using the software TPSDIG (http://life.bio. sunysb.edu/morph/morphmet/tpsdig2w32.exe), TPSRELW (Rohlf 1998) and MODICOS (Carvajal-Rodríguez \& Rodríguez 2005). Differences between ecotypes and environments were interpreted for the shell aperture (RW1) using a thin-plate spline representation, an interpolating function to describe shape changes with respect to the reference configuration (Rohlf 1998), using the TPSRELW software.

Statistical analyses. Geographical study: We first used a step-wise discriminant analysis to distinguish between morphotypes across the whole set of samples using the most relevant morphological shell variables (CS, U1 and U2, and a number of RWs including more than $90 \%$ of the variation in this local component: RW1 to RW7). The objective of this analysis was to determine which shell variables could be used to discriminate between the a priori defined (S and $\mathrm{E}$ ) morphs.

Second, we used a 3-way analysis of variance (ANOVA) to study the contribution of the different factors (and their interactions) to the morphological differences detected between morphs, following Underwood (1981) and Sokal \& Rohlf (1995). We used the 12 geographical samples described above to study mor- phological variability at different scales: localities (dozens of $\mathrm{km}$ ), shore levels (a few meters) and microgeographical replication (parallel transects). The ANOVA design included the factors Morph (fixed; with 2 levels, corresponding to S and E morphs), Locality (random; Cetárea, Silleiro and Corrubedo) and Transect (random; using the 2 parallel samples within shore level and locality) nested within the interaction between Morph and Locality. The dependent variables were chosen according to the results of the discriminant analysis, i.e. using those that better discriminated between morphs (CS and RW1; see below), in order to confirm the significance of the factor Morph and to determine its relative importance compared to the others. We checked for homoscedasticity (Levene test) before applying ANOVA and evaluated the use of transformed data (log-transformed, square root, arcsine) when it was not met following Underwood (1981). The percentage of variation explained by each fixed factor (or interaction) was estimated by the eta squared coefficient $\left(\eta^{2}\right.$; Sokal \& Rohlf 1995, Pierce et al. 2004, Conde-Padín et al. 2008).

Laboratory rearing study: We investigated the relative importance of phenotypic plasticity and inherited processes using a 2-way multivariate ANOVA (MANOVA) and a 2-way ANOVA, according to Scheiner (1993). We compared wildlife samples with laboratoryreared samples, in order to clarify how shell shape was affected by 9 mo of laboratory rearing. The MANOVA design included the factors Environment (fixed; field and laboratory) and Morph (fixed; upper and lower shore samples). The interaction between both factors was used to estimate the genetic-environmental interaction. The sum of the environmental and the interaction factors was included as the plastic response (Scheiner 1998, Conde-Padín et al. 2008). The same dependent variables used in the discriminant analysis, except size (CS), were used. We excluded size due to the impossibility of knowing age in wild specimens (see Conde-Padín et al. 2008). Variables showing the most outstanding differences between ecotypes were analysed with a 2-way ANOVA. The same procedures described in the geographical data analysis section were used to estimate the relative magnitude of factors in ANOVA and verifying homoscedasticity. All analyses were computed with the SPSS/PC statistical package (v. 14.01).

DNA isolation and AFLP genotyping: Total genomic DNA was extracted from the whole tissue of each individual using a modified version of Winnepenninckx et al. (1993) (see Wilding et al. 2001). After DNA quantification (Biophotometer, Eppendorf), samples were nor-

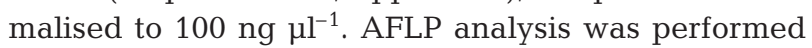
using a modified version of the procedure described by Vos et al. (1995). For each individual, $500 \mathrm{ng}$ of DNA 
were digested with 5 U EcoRI (New England BioLabs, NEB) and $3 \mathrm{U}$ MseI (NEB) in $25 \mu \mathrm{l}$ total volume of $1 \times$ NEB Buffer $2(50 \mathrm{mM} \mathrm{NaCl}, 10 \mathrm{mM}$ Tris- $\mathrm{HCl}, 10 \mathrm{mM}$ $\mathrm{MgCl}_{2}, 1 \mathrm{mM} \mathrm{DTT} ; \mathrm{pH} 7.9$ ) supplemented with $2.5 \mu \mathrm{g}$ of bovin serum albumin (NEB), for $4 \mathrm{~h}$ at $37^{\circ} \mathrm{C}$. Following enzyme inactivation at $70^{\circ} \mathrm{C}$ for $10 \mathrm{~min}, 25 \mu \mathrm{l}$ of a solution of $2 \times$ ligation buffer $(660 \mathrm{mM}$ Tris- $\mathrm{HCl}, 50 \mathrm{mM}$ $\mathrm{MgCl}_{2}, 50 \mathrm{mM}$ DTT, 10 mM ATP; pH 7.5; Roche) containing 5 pmol EcoRI adaptor, 50 pmol MseI adaptor and $0.4 \mathrm{U}$ T4 DNA ligase (Roche) was added and samples incubated for $16 \mathrm{~h}$ at $16^{\circ} \mathrm{C}$. The DNA fragments were pre-amplified with primers carrying 1 selective nucleotide (5'-GAC TGC GTA CCA ATT C+A-3' for EcoRI adapter and 5'-GAT GAG TCC TGA GTA $\mathrm{A}+\mathrm{C}-3^{\prime}$ for the MseI adapter) at a concentration of $20 \mathrm{pmol}$ on $4 \mu \mathrm{l}$ of 1:10 ligation dilution in $20 \mu \mathrm{l}$ volumes containing $2.5 \mathrm{mM}$ of $\mathrm{MgCl}_{2}, 187.5 \mu \mathrm{M}$ of each dNTP, $1 \mathrm{U}$ Taq polymerase (Bioline) in $1 \times$ PCR buffer (Bioline). PCR conditions were as follows: $94^{\circ} \mathrm{C}$ for $2 \mathrm{~min}, 20 \mathrm{cy}-$ cles of $94^{\circ} \mathrm{C}$ for $20 \mathrm{~s}, 56^{\circ} \mathrm{C}$ for $30 \mathrm{~s}, 72^{\circ} \mathrm{C}$ for $2 \mathrm{~min}$, and a final step of $60^{\circ} \mathrm{C}$ for $30 \mathrm{~min}$. The resulting product was diluted 1:10 and used for the second PCR amplification. This second PCR reaction was performed on $4 \mu \mathrm{l}$ of diluted PCR product in $20 \mu \mathrm{l}$ volumes containing $2.5 \mathrm{mM}$ of $\mathrm{MgCl}_{2}, 187.5 \mu \mathrm{M}$ of each dNTP, $8.3 \mathrm{pmol}$ of Eco+3 and Mse +3 primers and $1 \mathrm{U}$ Taq polymerase in $1 \times \mathrm{PCR}$ buffer. Cycling conditions for the second PCR were as follows: $94^{\circ} \mathrm{C}$ for $2 \mathrm{~min}, 10 \mathrm{cycles}$ of $94^{\circ} \mathrm{C}$ for $20 \mathrm{~s}, 66^{\circ} \mathrm{C}$ (decreasing by $1^{\circ} \mathrm{C}$ each cycle) for $30 \mathrm{~s}$, and $72^{\circ} \mathrm{C}$ for $2 \mathrm{~min}$, followed by $20 \mathrm{cycles}$ of $94^{\circ} \mathrm{C}$ for $20 \mathrm{~s}, 56^{\circ} \mathrm{C}$ for $30 \mathrm{~s}$, and $72^{\circ} \mathrm{C}$ for $2 \mathrm{~min}$, ending with $60^{\circ} \mathrm{C}$ for $30 \mathrm{~min}$. For each single individual, amplification reactions were performed with 2 primer combinations: MseI + CAA with FAM-EcoRI + AAT, MseI + CAA with HEX-EcoRI + AAG. The final PCR products were loaded with a GeneScan 500 ROX size standard onto an ABI Prism 310 Genetic Analyzer (Applied Biosystems). Fragment analysis and AFLP scoring was performed using GeneMapper v.3.7 software (Applied Biosystems). All DNA fragments $<50$ bp in length, $>500$ bp or $<70$ relative fluorescent units were excluded from the analysis (Holland et al. 2008, Galindo et al. 2009)

AFLP genetic analysis: Allele frequencies at 657 putative AFLP loci were estimated from the presence and absence of bands using a Bayesian method that assumes a non-uniform prior distribution of allele frequencies (AFLP-SURV v. 1.0; Vekemans 2002). The same software was used to estimate the percentage of polymorphic loci $(P L)$ at the $5 \%$ level and the expected heterozygosity $\left(H_{\mathrm{E}}\right)$ under the assumption of HardyWeinberg genotypic proportions. Pairwise distances among individuals were calculated using Nei's genetic distance (Nei 1972). The distance measure was used to generate a neighbour-joining tree with PAUP 4.0b (Swofford 1998). The level of support of each node was determined by 10000 bootstrap replications. We carried out a hierarchical partition of genetic differentiation within and between morphotypes using an analysis of molecular variance (AMOVA) as implemented in ARLEQUIN (Excoffier et al. 2005), using the procedure described for RFLP data. The analysis was repeated twice, using (1) variation within Morph nested within Transect and (2) variation within Transect nested within Morph. In that way we used the most powerful design on AMOVA to compare both Transect and Morph factors. The statistical significance of the genetic differentiation within each partition was determined via 10000 permutations using ARLEQUIN. In order to detect outlier loci presenting a signature compatible with adaptive selection in our AFLP dataset, we used the hierarchical Bayesian method implemented in the program Bayescan (Foll \& Gaggiotti 2008). The estimation of model parameters was automatically tuned on the basis of pilot runs (10 pilot runs, length 5000). Preliminary tests indicated that a burn-in of 50000 iterations was enough to have the Markov Chain Monte Carlo converging. The sample size was set to 10000 and the thinning interval to 50 as suggested by the authors, resulting in a total chain length of 500000 interactions. The loci were ranked according to their estimated posterior probability. Loci with a value over 0.99 were retained as outliers. This stringent criterion leaves very little room for false positives (Foll \& Gaggiotti 2008).

\section{RESULTS}

\section{Shell morphology in wild populations}

First, we verified whether our a priori defined morphotypes showed any diagnostic difference in shell shape components, using a step-wise discriminant analysis (Table 1). The analysis revealed a high rate of discrimination a posteriori (rate of cross validation was $>90 \%$ ). The variables showing the highest correlation with the discriminant function were CS and RW1.

Table 1. Melarhaphe neritoides. Discriminant analysis for morphotype along the geographical range. CS: centroid size, RW: relative warp, $U$ : uniform component. ${ }^{* *} \mathrm{p}<0.01,{ }^{* * *} \mathrm{p}<0.001$

\begin{tabular}{|cccc|}
\hline Wilks $\lambda$ & Cross validation (\%) & Variables & $\mathrm{r}_{\text {scores }}$ \\
\hline $0.29^{* * *}$ & 92.2 (upper) & CS & $0.827^{* * *}$ \\
& 97.2 (lower) & RW1 & $-0.631^{* * *}$ \\
& RW3 & $-0.425^{* *}$ \\
& U1 & $0.414^{* *}$ \\
& RW2 & $-0.325^{* *}$ \\
& & RW5 & $-0.263^{* *}$ \\
& & RW6 & $0.263^{* *}$ \\
\hline
\end{tabular}


The 3-way ANOVA on CS and RW1 was used to quantify the degree of shell variation between morphs, localities and transects (Table 2). All factors had a significant effect on CS. The most important was Transect, but as the other factors were tested against this, their effects were shown independently of the transect variation. The micro-geographical factor Morph was more important than the factor Locality, and the interaction was also significant and relatively large, suggesting certain variation among localities. This variation, however, did not interfere in the differences between morphs (Fig. 3, left). Again all factors were significant for RW1, with the micro-geographical factors (Morph) being larger than the factor Locality (Table 2). The Morph by Locality interaction was significant and as large as the Morph factor, although again it was caused by differences in the magnitude across localities rather than any inversion of the trend (Fig. 3, right). In summary, we observed a clear trend showing consistent differences between local morphs in size and RW1, these differences being more relevant than those observed among distant localities.
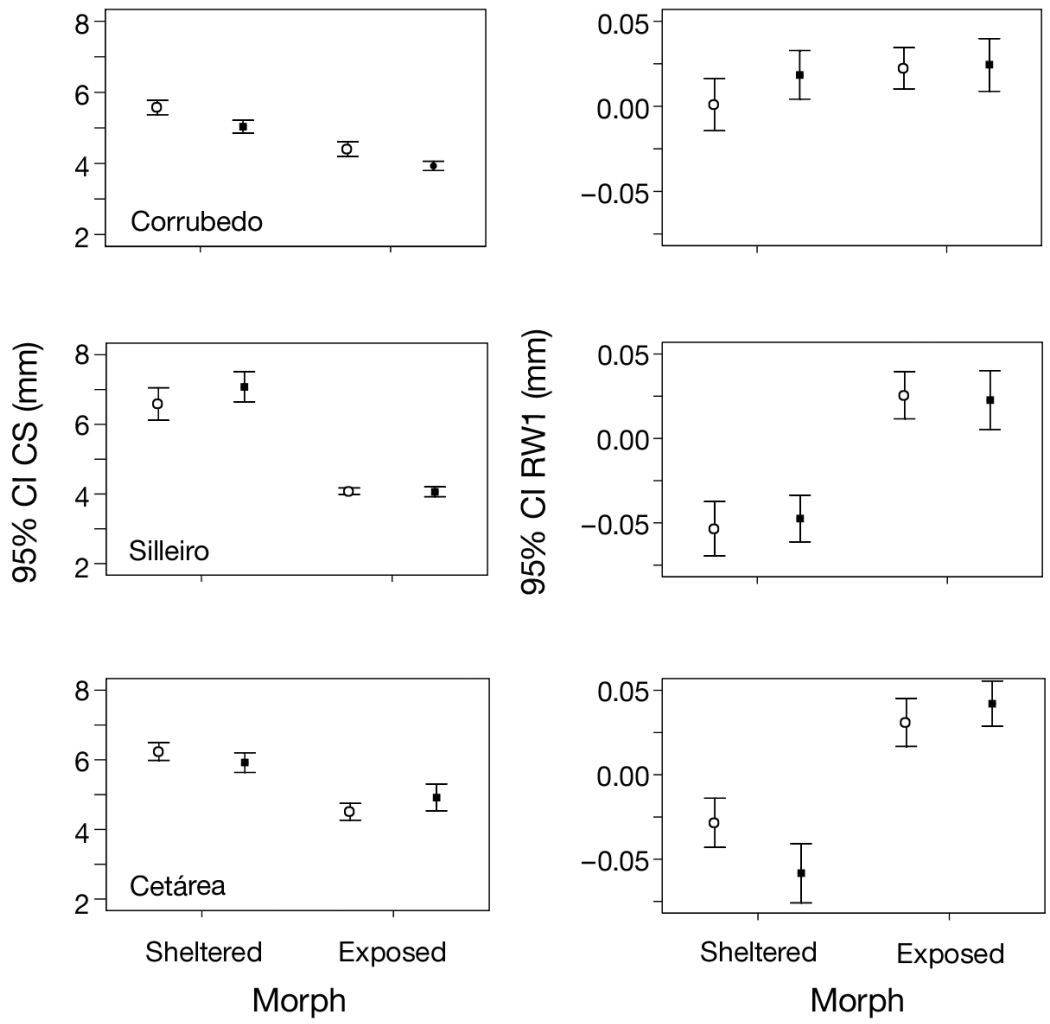

Fig. 3. Melarhaphe neritoides. The most distinctive morphological traits (centroid size, CS; relative warp 1, RW1; and size and shell aperture, respectively) between morphs. Sheltered $=$ morph from upper shore. Exposed $=$ from lower shore. $\mathrm{O}=$ transect $1 ; \boldsymbol{m}=$ transect 2 . Means $\pm 95 \%$ confidence interval $(\mathrm{CI})$
Table 2. Melarhaphe neritoides. Geographical analysis by a 3 -way analysis of variance for the variables' centroid size (CS) and relative warp 1 (RW1), including factors Morph, Locality and Transect nested within the interaction of Morph by Locality. SS: sum of squares; df: degrees of freedom; MS: mean square; $F$ : value of the $F$ test; Explained: percentage of $\eta^{2}$ of the factor in relation to the whole factors' sum. RW1 was homoscedastic, but despite different data transformations (log, square root, arcsine) homoscedasticity was not achieved for CS. The analysis is presented with both variables untransformed. ${ }^{*} \mathrm{p}<0.05,{ }^{* *} \mathrm{p}<0.01,{ }^{* * *} \mathrm{p}<0.001$

\begin{tabular}{|lrrrcr|}
\hline Source & SS & df & MS & $F$ & Explained \\
\hline CS & & & & & \\
Morph (M) & 276.7 & 1 & 276.7 & $107.3^{* * *}$ & $26.2 \%$ \\
Locality (L) & 38.1 & 2 & 19.0 & $7.4^{*}$ & $12.1 \%$ \\
M $\times$ L & 46.3 & 2 & 23.2 & $8.9^{*}$ & $25.9 \%$ \\
Transect & 15.5 & 6 & 2.6 & $4.7^{* * *}$ & $35.7 \%$ \\
Error & 190.6 & 348 & 0.5 & & \\
& & & & & \\
RW1 & & & & & \\
M & 0.283 & 1 & 0.283 & $176.8^{* * *}$ & $33.6 \%$ \\
L & 0.055 & 2 & 0.028 & $17.5^{* *}$ & $19.4 \%$ \\
M $\times$ L & 0.082 & 2 & 0.041 & $25.6^{* * *}$ & $33.3 \%$ \\
Transect & 0.021 & 6 & 0.003 & $2.19^{*}$ & $13.7 \%$ \\
Error & 0.557 & 348 & & 0.002 & \\
\hline
\end{tabular}

The thin-plate spline method allowed the biological interpretation of the geometrical deformation of negative and positive RW1 values (Fig. 4). The graphic representation showed that the samples collected at the exposed sites have a more rounded shell with a relative larger aperture than those collected at the protected sites. The same RW1 representation for corresponding ecotypes in Nucella lapillus and Littorina saxatilis are presented in Fig. 4, showing that the 3 species display convergent polymorphisms regarding the relative size of the shell aperture.

\section{Laboratory versus wild rearing}

In this experiment the factors Environment and Morph were used to partition the relative importance of environment and inheritance, respectively. A 2-way MANOVA was used for all shell variables except CS (Table 3), while a 2-way ANOVA was used for RW1. All factors had a significant effect, although Environment plus interaction (related to the plastic response) achieved nearly $50 \%$ of the overall changes in shape. This proportion is reduced to $<5 \%$ when focusing on 


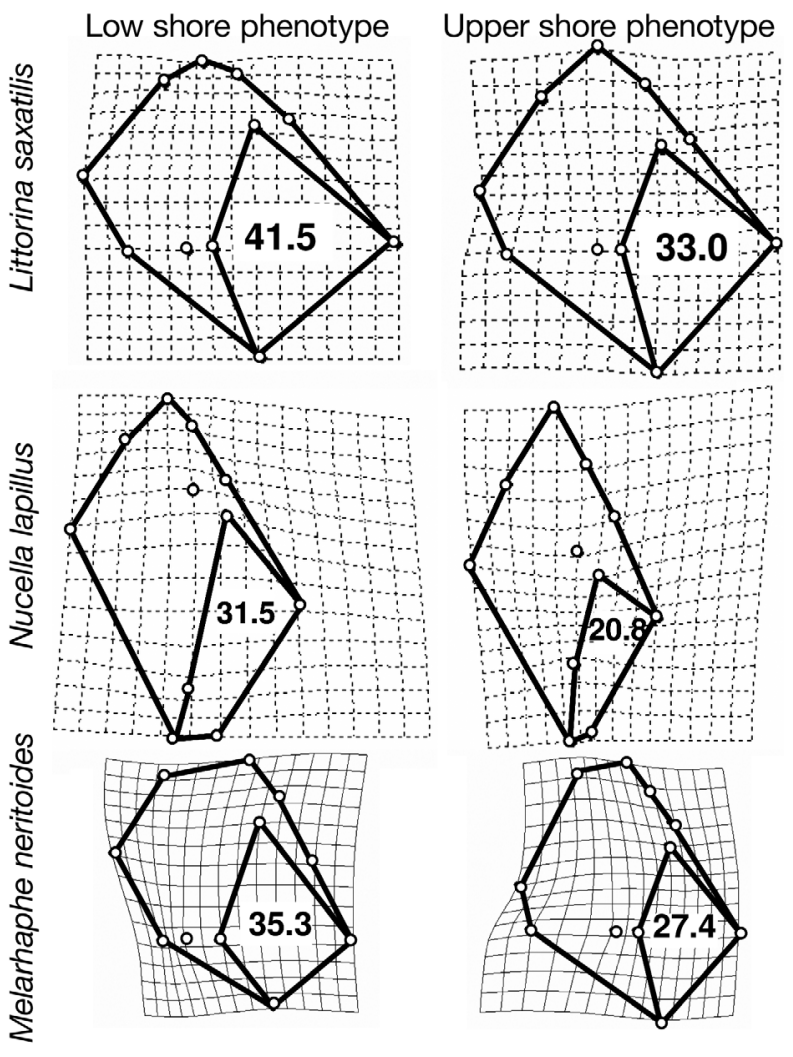

Fig. 4. Melarhaphe neritoides, Littorina saxatilis and Nucella lapillus. Thin-plate spline representation from TPSRELW software (Rohlf 1998), showing the most extreme negative (as in upper shore forms; Sheltered morph) or positive (as in lower shore forms; Exposed morph) deformations of the landmarks for $x$ - and $y$-axis in relative warp 1 (RW1, see Fig. 2) for the studied $M$. neritoides and 2 sympatric and related species ( $L$. saxatilis and $N$. lapillus). Some landmarks are connected by lines to facilitate the interpretation of the differences between morphotypes. Notice that the same polymorphism of shell shape is observed in every species living in the same microhabitat. Numbers refer to the percentage of the aperture in total shell area
RW1 exclusively. This suggests that most changes in RW1 were caused by genetic effects, or alternatively, by environmental effects acting in earlier stages (before sampling) in the specimens used in this experiment.

\section{Genetic analyses}

The percentage of polymorphic loci ranged between 66.4 and $72.9 \%$. Expected heterozygosity ranged between 0.19 and 0.21 . The neighbour-joining tree did not show any clustering pattern. The hierarchical analysis of molecular variance revealed a significant level of differentiation for AFLP at a micro-geographical scale $\left(2.8 \%\right.$ of overall variability, $\left.F_{\mathrm{ST}}=0.028, \mathrm{p}<0.001\right)$, probably due to the high migration rates expected to exist in the species object of this study. However, when inverting the AMOVA design, differentiation between transects within Morph was also significant and of similar magnitude than in the former partition ( $4 \%$ of overall variability; $\left.F_{\mathrm{ST}}=0.039, \mathrm{p}<0.001\right)$. This may suggest that ecomorph differentiation may be similar in magnitude to differentiation between transects (within Morph). In fact, when local pairwise comparisons between both morphs were performed, no locus was detected as being under adaptive selection using the program Bayescan. Most posterior probabilities of each locus were $<0.50$, far below the 0.99 value indicative of the presence of adaptive selection.

\section{DISCUSSION}

The shell polymorphism of Melarhaphe neritoides described in this study constitutes an interesting evolutionary phenomenon. On the rocky shores from NW Spain, 2 ecomorphs occur in sympatry. The typical micro-habitats of each morph are separated by just a few meters although the species has a high dispersal capability (Johannesson 1992). Along the Galician coast, a clear association of each morph with differential levels (and micro-habitats) of the rocky shore can be observed.

To our knowledge, this is the first study describing the existence of a sympatric (or micro-parapatric) shell polymorphism in this species, and 1 of the few known cases observed in marine planktotrophic species in general (Struhsaker 1968, Nevo et al. 1977, Schmidt et al. 2000, Schmidt \& Rand 2001, Aranzamendi et al. 2008). Two principal questions need to be ad- 
dressed to fully understand the origin and maintenance of this polymorphism: (1) its evolutionary meaning (adaptive or neutral) and (2) the evolutionary mechanisms that produced it (phenotypic plasticity or direct selection). Regarding the first question, the evidence available suggests an adaptive role for this polymorphism: (1) it shows the same convergent polymorphism observed in 2 other gastropod species (Fig. 4) living in the same micro-habitats and rocky shores (Johannesson et al. 1993, Rolán et al. 2004, Guerra-Varela et al. 2009) and (2) the morphological pattern observed along the geographical area studied was similar across an extensive geographical region. In fact we have observed the same polymorphism in localities separated by $>300 \mathrm{~km}$ from the sampling area and maintained during seasons and consecutive years. Such a polymorphism, being plastic or not, could not be maintained in the wild if it was not contributing to sustain adaptation. Finally, the observed polymorphism in shell aperture (captured by the RW1 measurement) can be functionally interpreted in adaptive terms. The wave-exposed micro-habitat of the low shore requires a larger muscular foot to better fix the specimen to the substratum, favouring a larger shell aperture in the E morph of Littorina saxatilis and Nucella lapillus (Conde-Padín et al. 2008, Guerra-Varela et al. 2009). In contrast, in the upper shore micro-habitat, desiccation stress may favour sheltered specimens showing a relatively smaller shell aperture (Carvajal-Rodríguez et al. 2005, Guerra-Varela et al. 2009). The polymorphism in shell aperture observed in Melarhaphe neritoides can be explained in the same terms as the other species (Fig. 4). A convergent polymorphism has been also described in 3 sibling species of the L. saxatilis complex from the UK, again being related with the rocky shore level (Reid 1993). However, the special interest of our study is how this can be produced in a species that can disperse over long distances. Moreover, the differences between morphotypes are not exclusively morphological. Both wild and laboratory-reared specimens of the E morph showed a behavioural preference to be under the sea water, while the $\mathrm{S}$ morph preferred to be above the water surface (E. Rolán-Alvarez pers. obs.). In summary, the evidence provided in this study supports the hypothesis that both size and aperture shell polymorphisms are adaptive in this species.

Regarding the evolutionary mechanism(s) that have caused the polymorphism, the results derived from this study do not allow excluding between phenotypic plasticity and direct selection to explain this mechanism. Two contradictory arguments, however, point out both hypotheses as alternative mechanisms.

We found significant differences between morphs for AFLP markers, although these differences were of the same magnitude as those between transects when changing the AMOVA design. In addition, we found no significant outlier loci between these morphs in the population studied. These results support a priori the plasticity argument, but should be interpreted with caution, due to the experimental limitations of the AFLP design. This pattern could change when including further populations or markers, and selection could be acting on a few major genes that are difficult to detect by this or most other methodologies.

In contrast, the laboratory results suggest a genetic basis for the polymorphism. Common garden experiments have been the classical design used to distinguish between genetic and plasticity effects (Scheiner 1993). In the present work, during 9 mo of rearing juveniles under the same environmental conditions, morph differences were maintained. Thus an important result arises from this study: although we cannot distinguish between direct selection and early imprinting, phenotypic plasticity after early development can be discarded for some shell shape components. Parental effects are fundamental to the ongoing integration of development, ecology and evolution, as they represent a particular form of plasticity arising from transmission of non-genetic developmental factors. If these effects are stable, they could involve permanent changes to gene expression. Paternity might provide a good opportunity for addressing the role of developmental plasticity and epigenetic inheritance for the origin and maintenance of complex adaptations (Uller 2008). In addition, the degree of phenotypic variation is genetically determined, and accordingly it is heritable and thus potentially able to evolve (Kaneko 2009).

Organisms faced with such environmental contrasts could adopt a discrete form of plasticity to adapt to each differential niche. There is evidence of plasticity as an explanation for variation in planktotrophic littorinids (Yeap et al. 2001). In temperate species, growth rate is known to influence shell form (Kemp \& Bertness 1984) and sculpture (Boulding et al. 1993). Previous studies in other gastropod species proved plasticity under a similar experimental design. Yeap et al. (2001) revealed changes in shell morphology in Nodilittorina australis transplanted at sizes between 8.5 and $19.4 \mathrm{~mm}$. Changes in the foot size have been reported after transplant experiments in Littorina obtusata (Trussell 1997), thus supporting plasticity of the developmental system.

Direct adaptive polymorphisms in marine organisms with high dispersal capabilities (planktotrophic stages) are rare but do exist. Two different shell sculptures in Littorina picta from Hawaii (currently Echinolittorina hawaiensis) represent ecotypes adapted to distinct ecological conditions (Struhsaker 1968, but see Reid 2007), although candidate genes of the process have not been detected with 1000 AFLP loci (D. Carlon pers. comm.). Nevo et al. (1977) observed that some allozyme variants in barnacles were associated with local 
temperatures. Schmidt et al. (2000) and Schmidt \& Rand (2001) demonstrated that an allozyme polymorphism was maintained in acorn barnacles by divergent selection acting along the intertidal gradient. In the same species, Dufresne et al. (2002) observed that certain geographical patterns in allozyme and microsatellite variation could be attributed to natural selection as well. Carlon \& Budd (2002) observed differential morphotypes in a scleractinian coral with opposite depth distributions associated with colony shape and corallite relief. They measured allele frequencies in allozyme loci and detected significant differences between groups. This pattern of selection on certain genetic markers is assumed to be exceptional, as morphological variation in species that disperse over long distances is expected to be preferentially environmentally induced (Parsons 1997, Kingsolver et al. 2002, Kruuk et al. 2003).

Alternatively, some evolutionary circumstances may favour the maintenance of genetic polymorphisms in sympatry even in species with a high dispersal capability (García-Dorado 1986, but see Gavrilets 2004), e.g. assortative mating prior to migration (Turelli et al. 2001). Partial isolation between ecotypes also enables natural selection to enhance existing differences between alternative morphs (Pfennig et al. 2010). Size assortative mating is a widespread phenomenon in many species (Crespi 1989, Erlandsson \& Rolán-Alvarez 1998, Hollander et al. 2005, Baldauf et al. 2009). In the case of Melarhaphe neritoides, the morphotypes meet and probably copulate in situ with specimens of the same morphotype, increasing the likelihood that the eggs and larvae released combine genes from the mother and father putatively adapted to the same microhabitat conditions. A protective condition for sympatric polymorphism is the possible differential habitat choice of the 2 morphs when the larva is ready to settle out of the plankton (García-Dorado 1986). Finally, the existence of high density and stable populations allows selection to be more effective with small selection coefficients (Hartl \& Clark 1997). Establishing the extent to which environmental factors can influence genome function is a critical condition to define their potential effects on long-term survival of individuals. The conclusions derived from this study will provide baseline data for future studies on this interesting model system.

Acknowledgements. We thank K. Tice, X. Pinto and D. Carlon for helpful comments on the manuscript and T. Muiños and N. Santa María for technical support during sampling and maintenance of specimens. We also thank to the ECIMAT field station for providing laboratory facilities and the following institutions for general funding: Ministerio de Educación y Ciencia (CGL2008-00135/BOS), Fondos Feder and Xunta de Galicia (INCITE09 310006 PR; Grupos de referencia competitiva 2010/80).

\section{LITERATURE CITED}

Aranzamendi MC, Sahade R, Tatián M, Chiappero MB (2008) Genetic differentiation between morphotypes in the Antarctic limpet Nacella concinna as revealed by intersimple sequence repeat markers. Mar Biol 154:875-885

Baldauf SA, Kullmann H, Schroth SH, Thünken T, Bakker TCM (2009) You can't always get what you want: size assortative mating by mutual mate choice as a resolution of sexual conflict. BMC Evol Biol 9:129-137

Bookstein FL (1991) Morphometric tools for landmark data: geometry and biology. Cambridge University Press, Cambridge

Boulding EG, Buckland-Nicks J, Alstyne KLV (1993) Morphological and allozyme variation in $L$. sitkana and related Littorina species from the northeastern Pacific. Veliger 36: 43-68

Britton JC (1992) Evaporative water loss, behaviour during emersion, and upper thermal tolerance limits in seven species of eulittoral-fringe Littorinidae (Mollusca: Gastropoda) from Jamaica. In: Grahame J, Mill PJ, Reid DG (eds) Proc 3rd Int Symp Littorinid Biol, London, p 69-84

> Britton JC (1995) The relationship between position on shore and shell ornamentation in two size-dependent morphotypes of Littorina striata, with an estimate of evaporative water loss in these morphotypes and in Melarhaphe neritoides. Hydrobiologia 309:129-142

Brönmark C, Miner JG (1992) Predator-induced phenotypical change in body morphology in crucian carp. Science 258: 1348-1350

Carballo M, García C, Rolán-Alvarez E (2001) Heritability of shell traits in wild Littorina saxatilis populations: results across a hybrid zone. J Shellfish Res 20:415-422

Carlon DB, Budd AF (2002) Incipient speciation across a depth gradient in a scleractinian coral? Evolution 56: 2227-2242

Carvajal-Rodríguez A, Rodríguez MG (2005) MODICOS: morphometric and distance computation software for evolutionary studies. Online J Bioinform 6:34-40. Available at http://webs.uvigo.es/acraaj/Modicos.htm

Carvajal-Rodríguez A, Conde-Padín P, Rolán-Alvarez E (2005) Decomposing shell form into size and shape by geometric morphometric methods in two sympatric ecotypes of Littorina saxatilis. J Molluscan Stud 71:313-318

Carvajal-Rodríguez A, Guerra-Varela J, Fernández B, Rolán E, Rolán-Alvarez E (2006) An example of application of the geometric morphometric tools to the morphological diagnosis of two sibling species in Nassarius (Mollusca, Prosobranchia). Iberus 24:81-88

Conde-Padín P, Grahame JM, Rolán-Alvarez E (2007) Detecting shape differences in species of the Littorina saxatilis complex by morphometric analysis. J Molluscan Stud 73: 147-154

> Conde-Padín P, Carballo M, Caballero A, Rolán-Alvarez E (2008) The relationship between hatching rate and number of embryos of the brood pouch in Littorina saxatilis. J Sea Res 60:223-225

Conde-Padín P, Caballero A, Rolán-Alvarez E (2009) Relative role of genetic determination and plastic response during ontogeny for shell-shape traits subjected to diversifying selection. Evolution 63:1356-1363

- Crespi BJ (1989) Causes of assortative mating in arthropods. Anim Behav 38:980-1000

Cronin MA, Myers AA, O'Riordan RM (2000) The reproductive cycle of the intertidal gastropod Melarhaphe neritoides on the west and south coast of Ireland. Biol Environ: Proc R Ir Acad 100B:97-106 
Darwin C (1859) On the origin of species by means of natural selection or the preservation of favoured races in the struggle for life. John Murray, London

DeWitt TJ, Scheiner SM (2004) Phenotypic variation from single genotypes. In: DeWitt TJ, Scheiner SM (eds) Phenotypic plasticity: functional and conceptual approaches. Oxford University Press, New York, NY, p 151-172

DeWitt TJ, Sih A, Sloan-Wilson D (1998) Costs and limits of phenotypic plasticity. Trends Ecol Evol 13:77-81

Dufresne F, Bourget E, Bernatchez L (2002) Differential patterns of spatial divergence in microsatellite and allozyme alleles: further evidence for locus-specific selection in the acorn barnacle, Semibalanus balanoides? Mol Ecol 11: $113-123$

Endler J (1986) Natural selection in the wild. Princeton University Press, Princeton, NJ

Erlandsson J, Rolán-Alvarez E (1998) Sexual selection and assortative mating by size and their roles in the maintenance of a polymorphism in Swedish Littorina saxatilis populations. Hydrobiologia 378:59-69

Etter RJ (1996) The effect of wave action, prey type, and foraging time on growth of the predatory snail Nucella lapillus (L.). J Exp Mar Biol Ecol 196:341-356

Excoffier L, Laval G, Schneider S (2005) Arlequin ver. 3.0: an integrated software package for population genetics data analysis. Evol Bioinform Online 1:47-50

Falconer DS, Mackay TFC (1996) Introduction to quantitative genetics. Addison Wesley Longman, Essex

Foll M, Gaggiotti O (2008) A genome-scan method to identify selected loci appropriate for both dominant and codominant markers: a Bayesian perspective. Genetics 180:977-993

Fordyce JA (2006) The evolutionary consequences of ecological interactions mediated through phenotypic plasticity. J Exp Biol 209:2377-2383

Fretter V, Graham A (1980) The prosobranch molluscs of Britain and Denmark. Part 5 - Marine Littorinacea. J Molluscan Stud 7:242-263

Galindo J, Morán P, Rolán-Alvarez E (2009) Comparing geographical genetic differentiation between candidate and noncandidate loci for adaptation strengthens support for parallel ecological divergence in the marine snail Littorina saxatilis. Mol Ecol 18:919-930

García-Dorado A (1986) The effect of niche preference on polymorphism protection in a heterogeneous environment. Evolution 40:936-945

- Garland T Jr, Kelly SA (2006) Phenotypic plasticity and experimental evolution. J Exp Biol 209:2344-2361

Gavrilets S (2004) Fitness landscapes and the origin of species. Princeton University Press, Princeton, NJ

Guerra-Varela J, Colson I, Backeljau T, Breugelmans K, Hughes RN, Rolán-Alvarez E (2009) The evolutionary mechanism maintaining shell shape and molecular differentiation between two ecotypes of the dogwhelk Nucella lapillus. Evol Ecol 23:261-280

Hartl DL, Clark AG (1997) Principles of population genetics. Sinauer Associates, Sunderland, MA

Holland B, Clarke AC, Meudth HM (2008) Optimizing automated AFLP scoring parameters to improve phylogenetic resolution. Syst Biol 57:347-366

Hollander J (2008) Testing the grain-size model for the evolution of phenotypic plasticity. Evolution 62:1381-1389

> Hollander J, Lindegarth M, Johannesson K (2005) Local adaptation but not geographical separation promotes assortative mating in a snail. Anim Behav 70:1209-1219

Hollander J, Collyer ML, Adams DC, Johannesson K (2006) Phenotypic plasticity in two marine snails: constraints superseding life history. J Evol Biol 19:1861-1872
Johannesson K (1992) Genetic variability and large scale differentiation in two species of littorinid gastropods with planktotrophic development, Littorina littorea (L.) and Melarhaphe (Littorina) neritoides (L.) (Prosobranchia: Littorinacea), with notes on a mass occurrence of $M$. neritoides. Biol J Linn Soc 47:285-299

> Johannesson K, Johannesson B, Rolán-Alvarez E (1993) Morphological differentiation and genetic cohesiveness over micro-environmental gradient in the marine snail Littorina saxatilis. Evolution 47:1770-1787

Johannesson K, Panova M, Kemppainen P, André C, RolánAlvarez E, Butlin RK (2010) Repeated evolution of reproductive isolation in a marine snail: unveiling mechanisms of speciation. Phil Trans R Soc B 365:1735-1747

Kaneko K (2009) Relationship among phenotypic plasticity, genetic and epigenetic fluctuations, robustness, and evolovability; Waddington's legacy revisited under the spirit of Einstein. J Biosci 34:529-542

Karban R, Baldwin IT (1997) Induced responses to herbivory. University of Chicago Press, Chicago, IL

Kemp P, Bertness MD (1984) Snail shape and growth rates: evidence for plastic shell allometry in Littorina littorea. Proc Natl Acad Sci USA 81:811-813

Kingsolver JG, Pfennig DW, Servedio MR (2002) Migration, local adaptation and the evolution of plasticity. Trends Ecol Evol 17:540-541

Kitching JA, Muntz L, Ebling FJ (1966) The ecology of Lough Ine. XV. The ecological significance of shell and body form in Nucella. J Anim Ecol 35:113-126

Kruuk LEB, Merilä J, Sheldon BC (2003) When environmental variation short-circuits natural selection. Trends Ecol Evol 18:207-209

Langerhans RB, DeWitt TJ (2002) Plasticity constrained: overgeneralized induction cues cause adaptive phenotypes. Evol Ecol Res 4:857-870

Lorenz K (1970) Studies in animal and human behavior. Harvard University Press, Cambridge, MA

Miner BG (2003) How to test whether phenotypic plasticity is adaptive. Ecological Society of America, Savannah, GA

Nei M (1972) Genetic distance between populations. Am Nat 106:283-292

Nevo E, Shimony T, Libni M (1977) Thermal selection of allozyme polymorphisms in barnacles. Nature 267:699-701

Parsons KE (1997) Contrasting patterns of heritable geographic variation in shell morphology and growth potential in the marine gastropod Bembicium vittatum: evidence from field experiments. Evolution 51:784-796

> Pfennig DW, Wund MA, Snell-Rood EC, Cruickshank T, Schlichting CD, Moczek AP (2010) Phenotypic plasticity's impacts on diversification and speciation. Trends Ecol Evol 25:459-467

> Pierce CA, Block RA, Aguinis H (2004) Cautionary note on reporting eta-squared values from multifactor ANOVA designs. Educ Psychol Meas 64:916-924

Pigliucci M (2001) The character concept in evolutionary biology. In: Wagner GP (ed) Characters and environments. Academic Press, San Diego, CA, p 363-388

Pigliucci M (2005) Evolution of phenotypic plasticity: Where are we going now? Trends Ecol Evol 20:481-486

Pigliucci M, Murren CJ, Schlichting CD (2006) Phenotypic plasticity and evolution by genetic assimilation. J Exp Biol 209:2362-2367

> Price TD (2006) Phenotypic plasticity, sexual selection and the evolution of colour patterns. J Exp Biol 209:2368-2376

Raffaelli D, Hawkins SJ (1996) Intertidal ecology. Chapman \& Hall, London

Reid DG (1993) Barnacle-dwelling ecotypes of three British 
Littorina species and the status of Littorina neglecta Bean. J Molluscan Stud 59:51-62

Reid DG (2007) The genus Echinolittorina Habe, 1956 (Gastropoda: Littorinidae) in the Indo-West Pacific Ocean. Zootaxa 1420:1-161

Remy JJ (2010) Stable inheritance of an acquired behaviour in Caenorhabditis elegans. Curr Biol 20:R877-R878

Rohlf FJ (1993) Relative warp analysis and an example of its application to mosquito wings. In: Marcus LF, Bello E, García-Valdecasas E (eds) Contributions to morphometrics. Museo Nacional de Ciencias Naturales (CSIC), Madrid, p 131-159

Rohlf FJ (1996) Morphometric spaces, shape components and the effects of linear transformations. In: Marcus LF, Corti M, Loy A, Slice D, Naylor G (eds) Advances in morphometrics. Plenum Press, New York, NY, p 117-129

Rohlf FJ (1998) TPSrelw: relative warps, version 1.20. State University at Stony Brook, NY. Available at http://life.bio. sunysb.edu/morph/morphmet/tpsrelww32.exe

Rohlf FJ, Bookstein FL (2003) Computing the uniform component of shape variation. Syst Biol 52:66-69

Rohlf FJ, Slice D (1990) Extensions of the Procrustes method for the optimal superimposition of landmarks. Syst Zool 39:40-59

Rolán E, Guerra-Varela J, Colson I, Hughes RN, RolánAlvarez E (2004) Morphological and genetic analysis of two sympatric morphs of the dogwhelk Nucella lapillus (Gastropoda: Muricidae) from Galicia (northwestern Spain). J Molluscan Stud 70:179-185

Rolán-Alvarez E (2007) Sympatric speciation as a by-product of ecological adaptation in the Galician Littorina saxatilis hybrid zone. J Molluscan Stud 73:1-10

Rolán-Alvarez E, Johannesson K, Erlandsson J (1997) The maintenance of a cline in the marine snail Littorina saxatilis: the role of home site advantage and hybrid fitness in ecotype formation. Evolution 51:1838-1847

Rolán-Alvarez E, Carballo M, Galindo J, Morán P and others (2004) Nonallopatric and parallel origin of local reproductive barriers between two snail ecotypes. Mol Ecol 13: 3415-3424

Sarkar S, Fuller T (2003) Generalized norms of reaction for ecological developmental biology. Evol Dev 5:106-115

Scheiner SM (1993) Genetics and evolution of phenotypic plasticity. Annu Rev Ecol Syst 24:35-68

Scheiner SM (1998) Evolution of phenotypic plasticity VII. Evolution in a spatially structured environment. J Evol Biol 11:303-320

Schlichting CD, Pigliucci M (1998) Phenotypic evolution: a reaction norm perspective. Sinauer Associates, Sunderland, MA

Schmidt PS, Rand DM (2001) Adaptive maintenance of

Editorial responsibility: Roger Hughes,

Bangor, UK genetic polymorphism in an intertidal barnacle: habitat and life history stage-specific survivorship of Mpi genotypes. Evolution 55:1336-1344

Schmidt PS, Bertness MD, Rand DM (2000) Environmental heterogeneity and balancing selection in the acorn barnacle Semibalanus balanoides. Proc R Soc Lond B Biol Sci 267:379-384

Sokal RR, Rohlf FJ (1995) Biometry. Freeman \& Company, New York, NY

Struhsaker JW (1968) Selection mechanisms associated with interspecific shell variation in Littorina picta (Prosobranchia: Neogastropoda). Evolution 22:459-480

Swofford DL (1998) PAUP*: phylogenetic analysis using parsimony (and other methods). Sinauer Associates, Sunderland, MA

Tollrian R, Harvell CD (1999) The ecology and evolution of inducible defenses. Princeton University Press, Princeton, NJ

Trussell GC (1997) Phenotyic plasticity in the foot size of an intertidal snail. Ecology 78:1033-1048

Turelli M, Barton NH, Coyne JA (2001) Theory and speciation. Trends Ecol Evol 16:330-343

Uller T (2008) Developmental plasticity and the evolution of parental effects. Trends Ecol Evol 23:432-438

Underwood AJ (1981) Techniques of analysis of variance in experimental marine biology and ecology. Oceanogr Mar Biol Annu Rev 19:513-605

Vekemans X (2002) AFLP-SURV version 1.0. Laboratoire de Génétique et Ecologie Végétale, Université Libre de Bruxelles

Vermeij GJ (1973) Morphological patterns in high-intertidal gastropods: adaptive strategies and their limitations. Mar Biol 20:319-346

Vos P, Hogers R, Bleeker M, Reeijans M and others (1995) AFLP: a new technique for DNA fingerprinting. Nucleic Acids Res 23:4407-4414

- West-Eberhard MJ (1989) Phenotypic plasticity and the origins of diversity. Annu Rev Ecol Syst 20:249-278

- West-Eberhard MJ (2002) Development and selection in adaptive evolution. Trends Ecol Evol 17:65

Wilding CS, Butlin RK, Grahame J (2001) Differential gene exchange between parapatric morphs of Littorina saxatilis detected using AFLP markers. J Evol Biol 14:611-619

Winnepenninckx B, Backeljau T, De Wachter R (1993) Extraction of high-molecular-weight DNA from molluscs. Trends Genet 9:407

Yeap KL, Black R, Johnson MS (2001) The complexity of phenotypic plasticity in the intertidal snail Nodilittorina australis. Biol J Linn Soc 72:63-76

Zelditch ML, Swiderski HD, Fink WL (2004) Geometric morphometrics for biologists: a primer. Elsevier Academic Press, London

Submitted: September 15, 2010; Accepted: January 12, 2011 Proofs received from author(s): March 18, 2011 